\title{
Assessing the Social Impact of the Public Realm in Waterfront Regeneration
}

\author{
Samira Awwal and Katharina Borsi \\ Dept. of Architecture \& Built Environment, University of Nottingham, United Kingdom
}

\begin{abstract}
Waterfront regeneration has become one of the major urban intensification strategies in the latter part of the 20th century. Typically, high-end residential and commercial properties are developed to ensure economic sustainability; complemented by cultural activities and retail, and an element of public space that attracts people to spend time by the water. The research aims to identify the social aspects contributing to the design principles of the good public realm in waterfront regeneration. It critically evaluates the framework through the case study analysis located in South Bank London. The methodology includes observational mapping to identify the specific factors for improved spatial quality supported by chronological architectural history and the regeneration policies. These factors contribute to the literature review with an understanding of the sectional articulation of cultural institutions as a type, morphologically specific anchor contributing to the social value of the urban design of the waterfront. The identification from the paper highlights the policy framework, generates a guideline for waterfront regeneration in developing countries and gives a base for future research opportunity in a populated city, Dhaka, Bangladesh. The result shows an expected social influence in the problem area generated by the indicative implementation of policies in the waterfront.
\end{abstract}

Keywords: Urban Regeneration, Waterfront regeneration, Public realm, Social aspect, Sustainability, Urban Infrastructure

\section{Introduction}

The waterfront areas play a significant contribution in molding a city's structure. A successful waterfront regeneration helps in creating a sustainable city for the future.

"Cities seek a waterfront that is a place of public enjoyment. They want a waterfront where there is ample visual and physical public access - all day, all year - to both the water and the land." (Department of Planning and Design of Edge Environments, 2012)

The public realm plays a vital role in waterfronts (Gehl, 2010). The activity is generated in a public realm which influences the social and economic condition of the area. The social aspect is often neglected in the design process, which leads to a failure of a place. The thesis gives a brief idea about the waterfront regeneration and how the social aspect is influencing the regeneration in making a successful public realm. The process includes a thorough understanding of the existing functions in the study area, South Bank London, located at the centre of the capital. It includes an extensive study of the feasibility of the pathway and socially interactive place in the riverfront. The research uses observational mapping for the understanding of the dense sectional integration of cultural institutions linked with waterfront to generate a good public realm. It also argues, that the PPS Framework and public realm policies described by Jan Gehl does not include the social impact and the sectional articulation anchoring with the urban design of the waterfront, which is needed to activate the place. The research aims to understand the social aspects of waterfront regeneration and critically evaluate the theoretical framework and findings from the case study analysis. It will apply the framework in a congested waterfront area, suggesting ways to enhance its social value and providing a base for future research opportunities 


\section{The Research Methodology}

The methodology comprises of qualitative and quantitative approach in conducting the research. The author used place-centred behavioural mapping to identify the activities that impact the social aspect of the case study area. The author argues that the identification of social aspects is not considered in the literature review of urban waterfront by a comparative analysis between the literature review set and the case study based on given parameters.

\section{Literature Review}

This section delivers three sets of literature for the research, focusing on the social aspects of a public realm in a waterfront project.

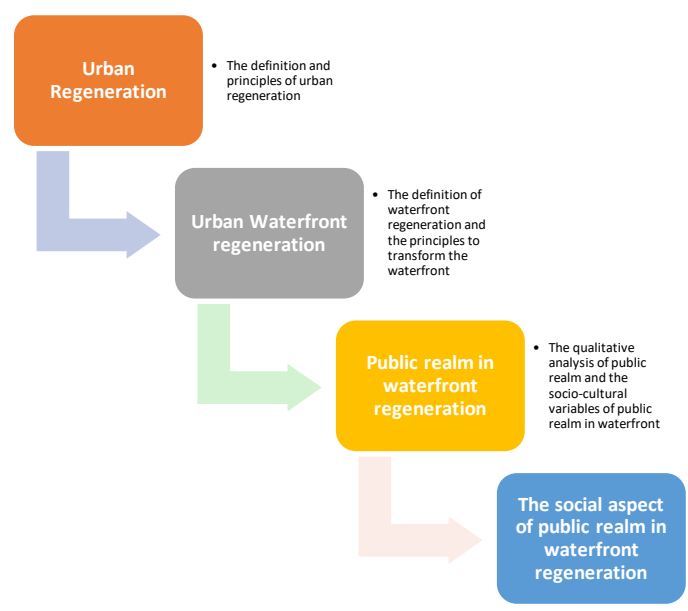

Figure 1 The sequence of theory to support the research (Author, 2019)

\section{Urban Regeneration}

Urban regeneration is the redevelopment of decaying urban areas in cities. Every city has decaying urban areas, which needs to be addressed and brought to light for attention. Urban regeneration is the complex process of solving the problems of those areas, which is mainly implemented by the funding from the public sector. The urban renewal mostly started in the $19^{\text {th }}$ century. The process has an immense impact on the history and demographic condition of a city.

The cities are always regenerative. Urban change is closely linked with the theories of urban problem and opportunities (Hussein, 2015).

"Comprehensive and integrated vision and action which leads to the resolution of urban problems and which seeks to bring about a lasting improvement in the economic, physical, social and environmental condition of an area that has been subject to change." (Roberts, 2000, p. 17)

\section{Urban Waterfront Regeneration}

According to (Yassin et.al., 2010), "the urban waterfront is defined generally as the area of communication between urban development and the water". The two major elements of the waterfront are water and land. The urban waterfronts are located at the heart of the cities. The mixed-use developments are necessary to generate a successful waterfront (Timur, 2013). 


\section{Transformation of Urban waterfront}

According to PPS (Project for Public Spaces, 2009), there are some principles for waterfront regeneration which can make the place dynamic and lively. These principles are discussed below.

The waterfront should be a public property which will increase community engagement. Establishing public goals should be the primary aim of the regeneration. The vision for the shared community can be flexible or adaptable and can be implemented sequentially. Several functions can be provided in one place. These functions give visitors several destinations to go to. Each destination generates diverse and layered activities. All the destinations should have a common vision for the waterfront. The primary objective is attaining continuity, mainly in pedestrian experience. The walkable waterfront alongside the water body with a variety of activity will zestfully attach destinations to reinforce each other. Housing, parks, entertainments, and retail is involved in the regeneration process which makes it a great challenge. The accessibility to the waterfront plays an important role. Waterfront needs to have continuous public access without any interruption. The waterbody should be accessible by people in many ways ( refer to Fig 2). Swimming, walking on the bank, fishing, or riding boats can make the place interacting to visitors and tourists. Any waterfront development project should incorporate the community' vision as the primary goal. The development must not interfere with any pedestrian movements. The waterfronts cannot just be developed only in terms of growth and change, but it is necessary to develop the project as a flourishing waterfront.

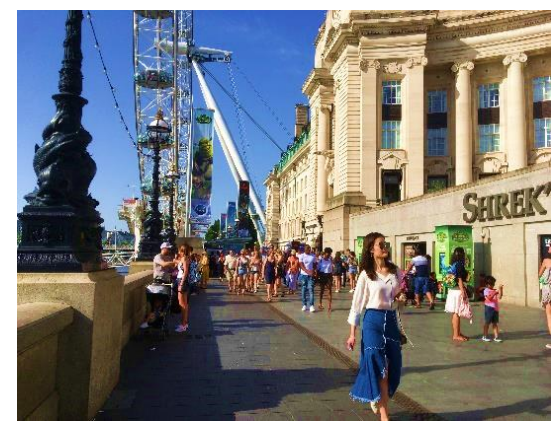

Figure 2 View from Westminster Entry to the London Eye (Author, 2019)

Residential development near the waterfront area diminishes the waterfront use. Large consolidation of residential function hinders the activities to happen in the waterfront area (refer to Fig 3). The vitality of the waterfronts can be hindered by passive open space. The waterfronts can use parks as a connecting tissue, to interlink several destinations. The commercial and public-use buildings should be placed in front of the waterfront to generate activity. Tower buildings with residential functions may affect the vitality of the waterfront. Waterfronts are adequately amplified when there are enhanced pedestrian and bicycle facilities. These two are very important factors in transportation. Pedestrian promenades and bicycle lanes are both functional and attractive feature of any waterfronts. With these functions, waterfronts are active, and vitality can be achieved. 

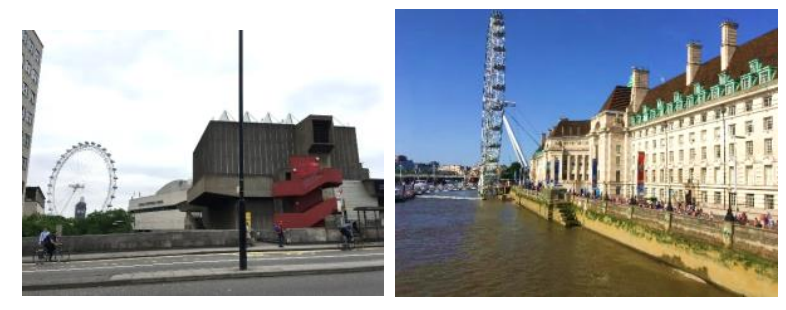

Figure 3 The iconic London Eye from the Waterloo entrance and Westminster Bridge (Author, 2019)

There should be different seasonal activities and adequate amenities should be provided to maintain the vitality within the area. The cold or rainy season should not be a hinder to the activities. The waterfronts which will be active throughout the year will bring the economic benefits and higher engagement in the public activities. An iconic structure can be provided to the waterfront, which will be an attractive destination to the place. The iconic structure at the waterfront also gives a strong sense of place. To achieve flexibility and people spirited presence, an iconic structure works as a multi-use destination (Project for Public Spaces, 2009).

\section{Good Quality Public Realm in the waterfront}

The public realm refers to the term 'public domain' or 'external urban spaces' which can be accessed by the public without any restrictions.

The public realm embraces the external places in our towns and cities that are accessible to all.

These are the everyday spaces that we move through and linger within, the places where we live, work and play. (Atkins, 2018)

The human interaction outside their home in certain places can also be described as 'public realm'. The places are used by people for socializing, playing, working, shopping, eating, and other social activities. (Gehl, 2010).According to (Ipswich, 2018), there are many cultural facilities which strengthen the waterfront identities. Public realm design with detailed design element would improve the public realm by creating more heritage value. The inclusion of public activity alongside the waterfront (refer to Fig 4) would make the place more vibrant. Providing a place for events and performance, informal play areas will help to achieve vitality.

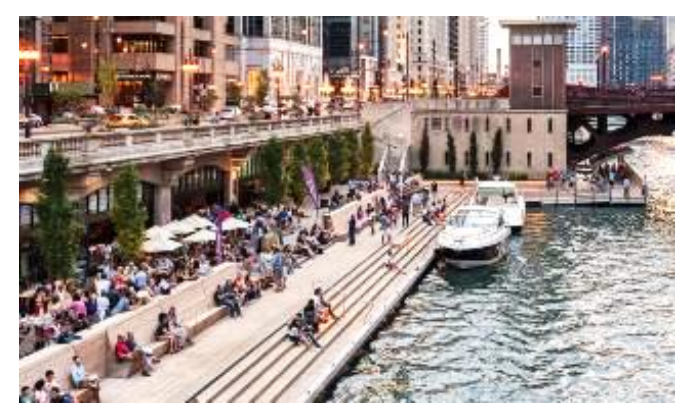

Figure 4 The public activity in the waterfront in Chicago (choosechicago.com, 2019)

The waterfront is benefitted by excellent pedestrian walkways. If the walkway is strengthened by interlinked routes to the city centre and access to green public areas, it will facilitate the realm. Increasing pedestrian facilities will help the reduction of vehicles in the area. A place is navigated visually by the people through the landmarks and key public spaces. Increasing the vibrancy in the waterfront will attract more visitors to the town. It can be achieved by reinforcing spaces, nodes, main routes, and gateways. A natural way of legibility for walking and cycling can also be achieved by landmarks and other features. 


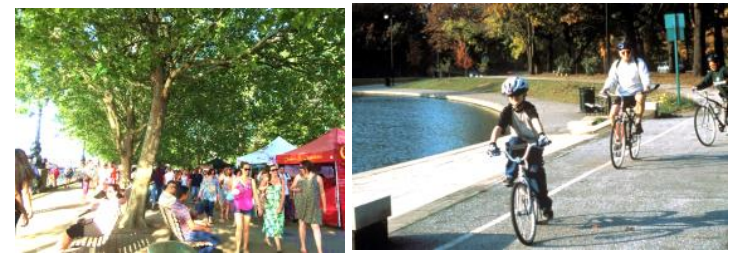

Figure 5 The public activity on the South Bank during the weekend (Author, 2019) Figure 6 The Bicycle movement along the waterside in Cleveland, Ohio (Project for Public Spaces, 2009)

Designing a place needs to be human-scaled (refer to Fig 5). Spaces and routes need to be human proportioned, so any betterment is possible. This makes a place accessible to its dwellers with proper shade and shelter. Safety and security can also be maintained properly. The infrastructure of the waterfront should be improvised in the existing structure and connection should be made from the city centre to the waterfront. Providing cycle parking near the waterfront will also increase the feasibility of providing bi-cycle routes. The city must be accessible by all. Any form of transport; walking, cycling or motorized vehicles need to be used for transport. Establishing a proper vehicular movement from the waterfront area is very important (refer to Fig 6).

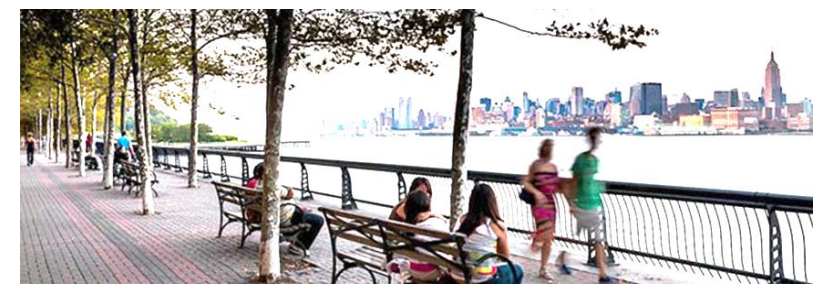

Figure 7 The public activity in South Bank (The waterfront blog, 2016)

The public realm in the waterfront will always be improved if that place has several green areas and plantation. Small scale places with a plantation, provision of new green space within developments and existing green in the river frontage help to make the area aesthetically beautiful and environmentally clean. Use of different material palette (refer to Fig 7) and appropriately in certain areas will help to increase the vitality in a different pattern in the waterfront. The materials need to be resilient with options of proper maintenance and repair as well (Ipswich, 2018). Ipswich argued that these parameters can work as an addition to the PPS Framework to transform the waterfront.

\section{The social dimension of the public realm in waterfront Regeneration}

The social dimension in waterfronts plays an important role in the community's livelihood. The urban waterfront demonstrates the historic modification of land water-uses along the edges of the waterbody of cities. According to (Rauno Sairinen, 2005), the social impact assessment can be analyzed under the following categories:

\section{a. Resources and identity}

Major attributes and vitality of the area

-Assessment of the environmental, cultural or historic values

-Connotation to the visual, social, and cultural identity (city image, community identity)

\section{b. Access and activities}

-Are the waterfront areas reachable to the public?

-What kinds of activities are possible? (Water dependency)

-Easy or difficult access to the waterfront?

-Traffic and parking questions; waterfront routes 


\section{c. Social status}

-For whom (social, age or ethnic groups) are the housing and service areas planned and built?

-Role of social/private housing

-Partition and/or gentrification processes

\section{d. Waterfront experience}

-Presence of waterbody (sea, lake, river, etc.)

-Restorative experiences, the importance of visual messages, physical touch, tastes, voices, moving in the space, sense of transition as recognition (Rauno Sairinen, 2005, p. 125)

Vitality, Safety, and Social Sustainability

The city should be lively. The public spaces need to be active and users need to have interaction with the spaces. The social and recreational activities should be supported by good pedestrian and vehicular connection and convenience to engage in urban movements (Gehl, 2010).

\section{A. Vitality}

The waterfront needs to be an active place where the place is connected with a good pedestrian connection. The city is successful when it can concentrate or scatter people gatherings according to the city's need and generate vitality (Gehl, 2010). According to Gehl, the following characteristics are needed to achieve vitality:

- $\quad$ Active ground floor policy

- Interactive façade

- $\quad$ Soft edges

- $\quad$ Pedestrian movement and slower traffic

- Sufficient public transportation to the site

\section{B. Safety}

Any public space has to be safe for people. The pedestrian walkways and walkway in front of the waterfront needs to be safe. (Jacobs, 1961). The following characteristics are:

- $\quad$ Priority for pedestrians in mixed traffic

- Clear defining structures

- The soft transition between public and private spaces

\section{Social Sustainability}

The concept of social sustainability refers to equal convenience for accessing the public realm and urban spaces. Social sustainability also means to prioritize equivalency in meeting other people in public spaces. The waterfront area will have to be accessed by all kind of people without any obligation (Gehl, 2010).

\section{Summary of the literature}

A good quality waterfront needs to share public goals as the main objective for a shared community (Project for Public Spaces, 2009). The waterfront can generate activity when given multiple destinations and those destinations are interconnected. (PPS, 2008). According to (Gehl, 2010), the city becomes safe when the pedestrian movement is prioritized. Promoting different mode of transportation is needed for all type of people to come into the place. The commercial and recreation function creates public area whereas the residential functions create private spaces. So, limiting residential function in the waterfront is one of the major concerns while regeneration (Bruttomesso, 2001). A good public realm needs to have a place for seasonal activities to make the place animated. The landmark or standalone structure or iconic buildings works as a boon to the waterfront (PPS, 2019). The understanding from the literature has been used in the case study to identify the regeneration policies that had been applied, which is mentioned in the critical analysis. 


\section{South Bank London, United Kingdom}

\section{Brief description of South Bank}

The London South Bank is one of the most popular urban areas in the world. It is an economic and entertainment district in Central London. The South bank is generally considered to be bounded in between the Westminster Bridge and the Black friars' bridge. (Farrell, 2010).

\section{South Bank as a cultural centre}

South bank has played an important role in cultural regeneration in the post-war period. The post-war buildings create distinctiveness and contribute architecturally to the site (refer to Fig 8).

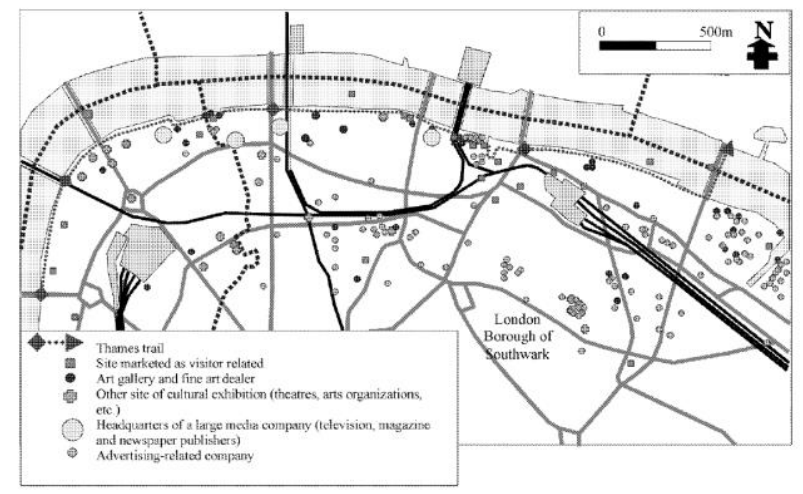

Figure 8 Type of people and activities on the South bank (Smith, 2000)

The royal festival hall has been regenerated and incorporated the spirit of the 1950s. The open space and the tactile materials used in the details of the buildings portray strong architectural specifics. The Hayward Gallery and the Queen Elizabeth hall also give a relentless interpretation of 1960's culture. On the other hand, the National Theatre works like a connecting building between the south bank and the waterloo bridge. The building is connected at the mid-level with Waterloo Bridge by a tunnel beneath, but it is separated at the river and bridge level (Tompkins, 2008).

The South Bank constitutes of various functions which induce animation on the site. The northwest part consists of govt. offices, commercial buildings hotels and Charing Cross station (refer to Fig 8).

The riverside area, which is the South bank conservation area, consists of cultural buildings, open spaces, sculptural administrative buildings, and landmarks (refer to Fig 9) (Ilieva, 2012).

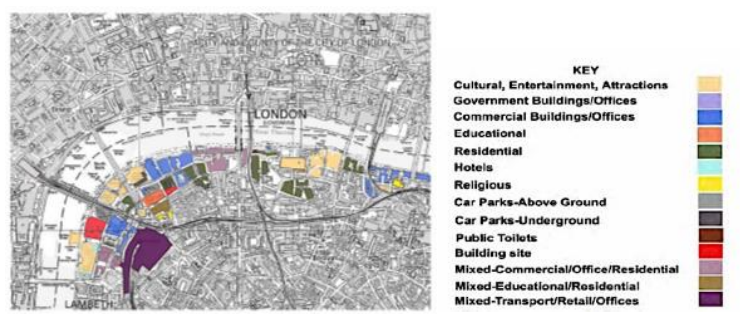

Figure 9 Land Use map of South Bank (Ilieva, 2012) 


\section{Spatial Analysis after Regeneration}

The spatial analysis of the South Bank includes building massing, land use, circulation pattern, public and open space and overall synthesis diagram of the place (refer to Fif 10).

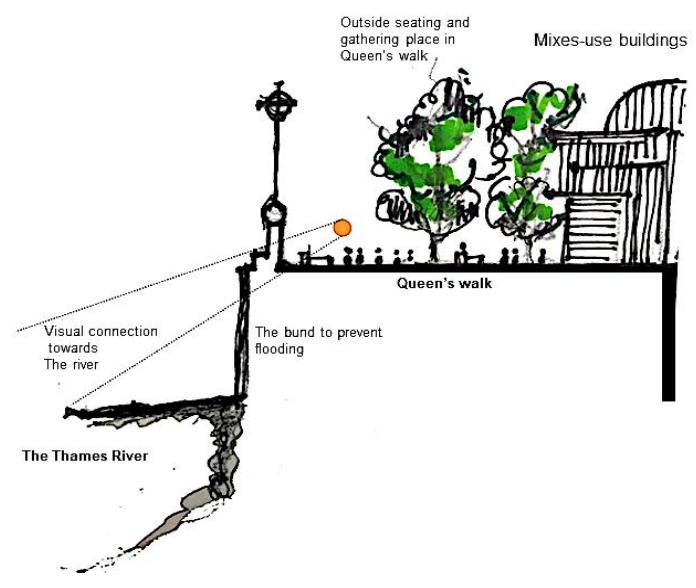

Figure 10 Street section of South Bank (Author, 2019)

The spatial analysis consists of massing, open urban spaces, connectivity, and circulation, open and green spaces on the bank. From the history, it is evident that South Bank was regenerated to make the site as the cultural centre. The study area was from Westminster Bridge to Black friar's bridge. From the PPS framework discussion, it is seen that having civic goals as the primary objectives and multiple functions at one site is important to activate a waterfront, which has been used in the South Bank.

\section{A. Connectivity and circulation}

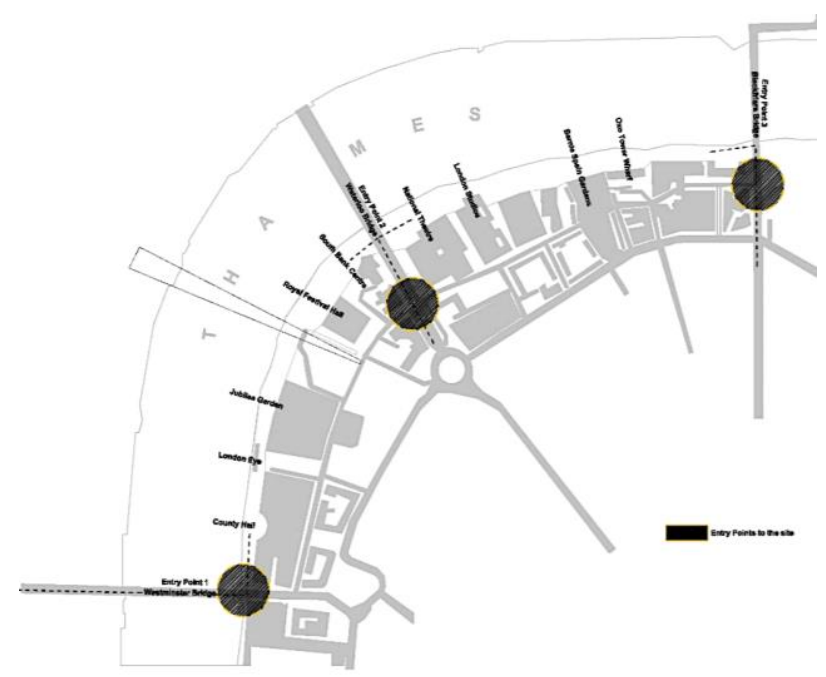

Figure 11 Major Entry Points in the Site (Author, 2019)

The site is connected with the tube stations at three different points. It is also accessible from Embankment and Charing Cross station from the other side of Thames. The site is well connected with vehicular access and public transport is easily available. The tourists and Londoners can access the site through all means of transport. 


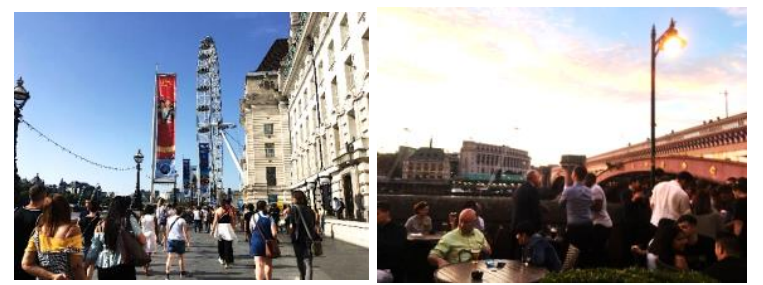

Figure 12 Westminster Entry Point (Author, 2019) Figure 13 Black friars Entry Point (Author, 2019)

From Figure 12, it is shown that the huge iconic structure on the sire is the London Eye, which attracts tourists on the site. The stand-alone iconic structure is one of the frameworks, which was followed on the bank

\section{B. Circulation on the site:}

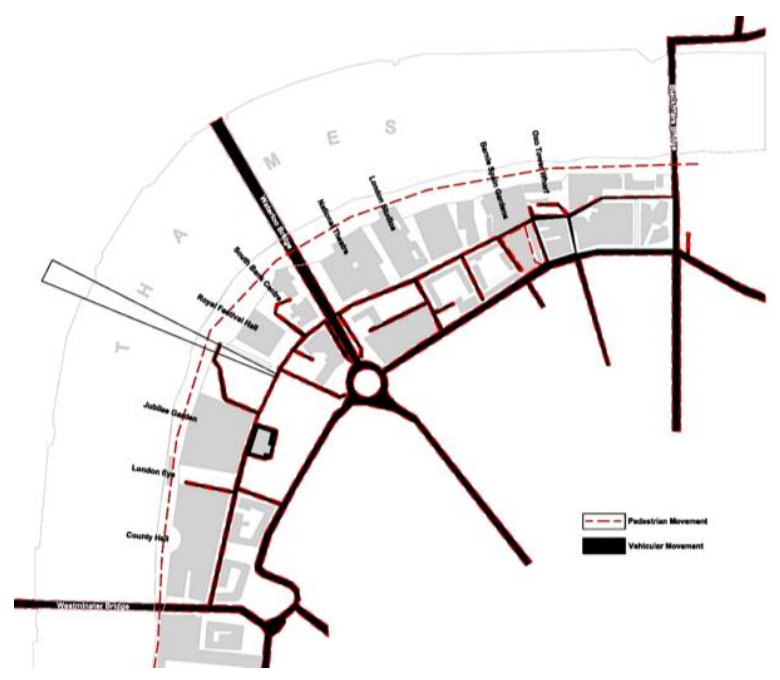

Figure 14 Circulation diagram of the South Bank (Author, 2019)

The diagram (refer to Fig 14) shows the vehicular and pedestrian movement in and around the site. On the bank side, there is no vehicular access other than low moving service vehicles. The pedestrians and bicyclers enjoy the riverside while walking or riding the cycle without any hazard of vehicular movement. Also, as the site is completely pedestrianized, the children can move safely without supervision. The upper analysis shows the different entry points and different modes of public transport along with pedestrian and bicycle circulation in the site, which follows the PPS Framework. 


\section{Open Space and Green Space}

There is two major green space alongside the area, the Jubilee Garden and the Bernie Spain Gardens (refer to Fig 15 \& 16).

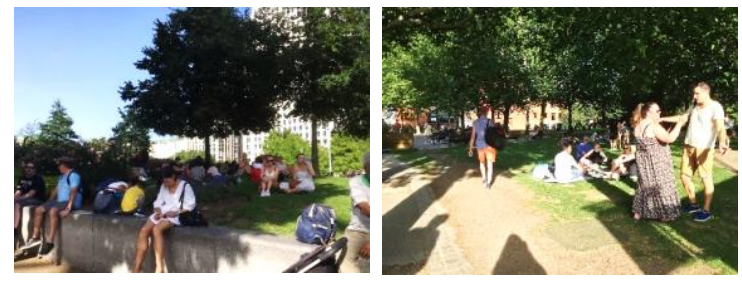

Figure 15 Public activity in Jubilee Garden (Author, 2019) Figure 16 Public Activity in Bernie Spain's Garden (Author, 2019)

The whole riverside walkway is considered as a public space bund. There is sufficient plantation (refer to Fig 17) which has been shown in the above diagram.

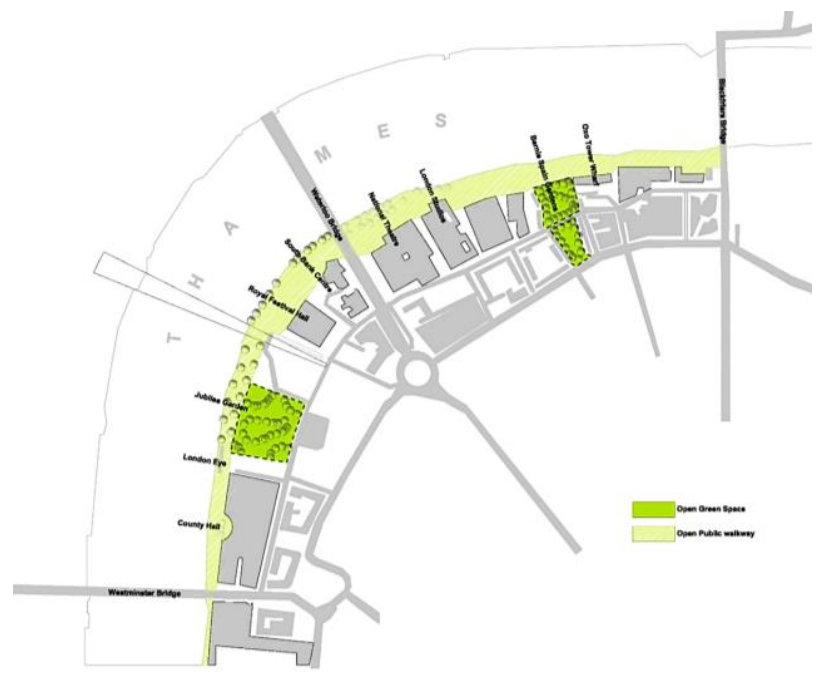

Figure 17 Green Area and Open space Diagram (Author, 2019)

\section{Hierarchy of circulation and open space diagram}

Fig 18 shows the open green spaces, the Queen's walk, and entry points to the study area together. The PPS Framework mentions about bridging the destinations and connecting them by open space. The diagram shows the pedestrian movement in and along with the site which is a bridge to all the destinations. The vehicular movement is marked in the site in context with other activities and building masses, which sums up the upper four diagrams. 


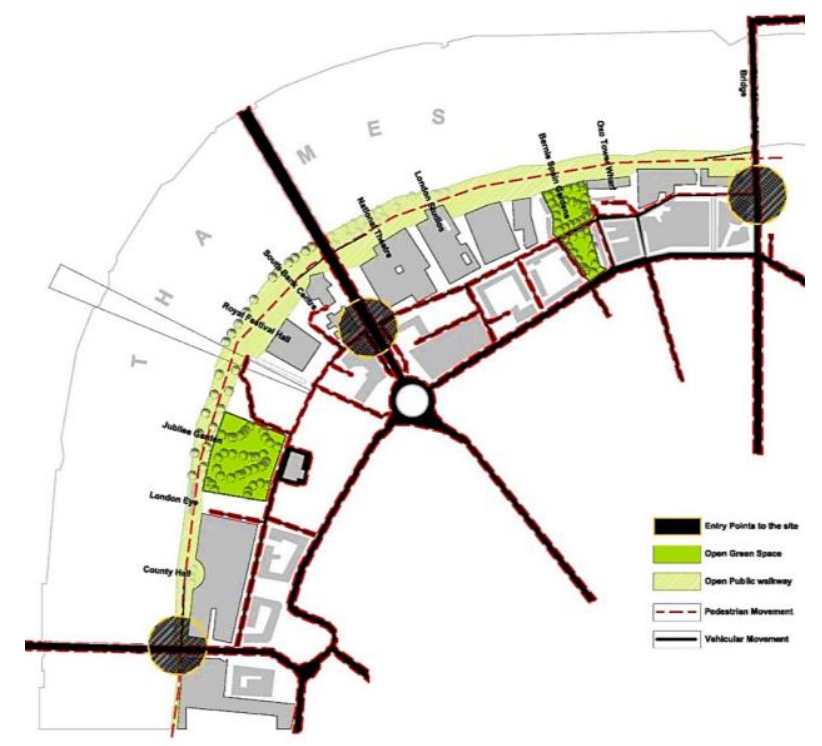

Figure 18 The synthesis of activities and open space in South Bank (Author, 2019)

\section{Analysis of the key sites}

From the diagrams and supporting pictures, there are some key sites, which holds importance in the site for vitality (refer to Fig 19).

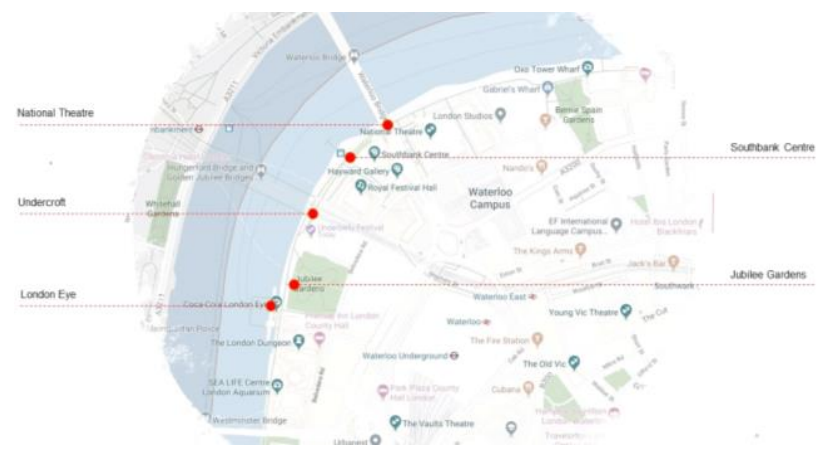

Figure 19 Key Site areas in the bank (Author, 2019)

For an in-depth understanding of the sectional integration at the site, the South Bank Center, the Royal Festival Hall and the London Eye will be described in detail. The South Bank Center has four iconic buildings, of which the RFH holds the history of Festival of Britain. The London Eye acts as the iconic landmark of the site.

\section{A. The Southbank Centre}

Southbank Center is one of the major building which culturally dominates the site. The land area for the centre is 30 acres surrounded by Waterloo Bridge, river Thames and the London Eye. 


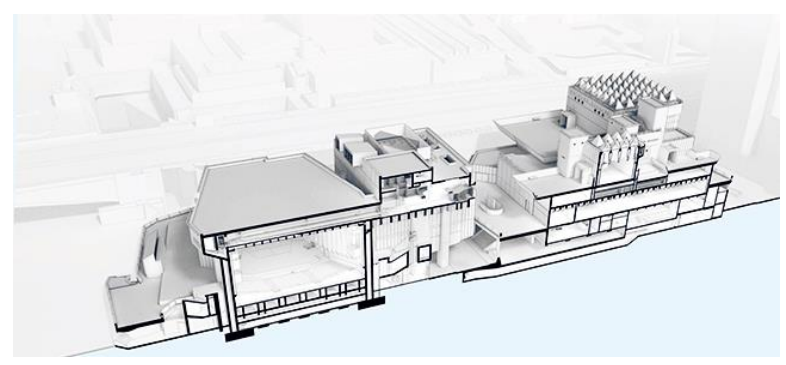

Figure 20 Sectional perspective of South Bank Center (Cousins, 2017)

The south bank centre has four major parts: RoyalFestival Hall (originated from Festival of Britain), Queen Elizabeth Hall, Hayward Gallery and Purcell Room (refer to Fig 20) (Aelbrecht, 2017)

\section{Declination of the regeneration:}

South bank centre is one of the most controversial regeneration projects in post-war modernist culture. It witnessed declination to regeneration from heritage point and the local community. The Royal festival hall which is originated from Festival of Britain in 1951 and the other three 1960's brutalist structures endured so many hazards of demolition. Despite the controversies, the London plan (Prof. Patrick Abercrombie) nominated the Southbank as the centre for culture. After the festival, the power transferred to conservative from labour. The London plan started to fall into place after the festival of Britain (Leventhal, 1995). The decisions taken are the following:

- $\quad$ All the buildings other than the Royal Festival hall were to be demolished.

- To remake the South bank as a cultural centre

- $\quad$ LCC declared that the RFH should be expanded as a late modernist cultural centre.

- $\quad$ Creating a walkway for connection in between the buildings (refer to Fig 22) (Aelbrecht, 2017).

Failure to redevelop the SBC: There were many failed attempts to redevelop the South Bank centre.

- In the 1970s the RFH Ballroom has been promoted.

- $\quad$ After that, the decision for open foyer in NT inspired the designers to create a provision for open large foyers in the centre which can generate animation.

- In the 1980s the SBC started to regenerate its public spaces.

- The initial attempts to regenerate the building tried to use ornamentation or colour to hold the postmodern style architecture (Aelbrecht, 2017).

The first masterplan and new design strategy: There was a framework for implementation, divided into two phases. The first phase looked into the developments of public realm which includes:

- $\quad$ Removal and replacement of servicing area

- Generating active frontage

- $\quad$ Generating new public spaces

The 1st phase development successfully changed the public realm in the Queen's walk. The festival of Britain in 2011 has majorly helped in the restoration of the active ground floor policy in SBC (Aelbrecht, 2017). 


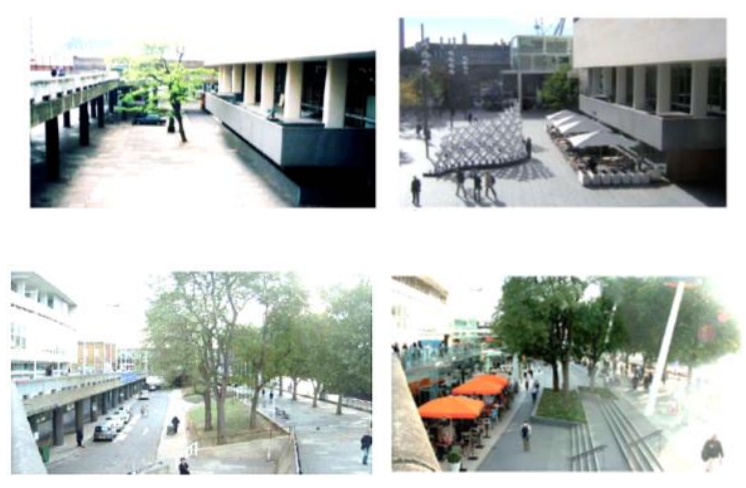

Figure 21 The Before After images of South Bank Center (Tompkins, 2008)

\section{B. Royal Festival Hall}

The royal festival hall is the most influential building from the post-war period which has been conserved. The RFH was built during the Festival of Britain. The functions in the building included bars, restaurants, ballroom, and reception for public access (McKeen, 1992).

\section{Regeneration of RFH:}

There were two major refurbishments in the Royal Festival. The 1st alteration happened in 1964. And the 2nd alteration happened in 2005 (Tompkins, 2008). The following developments were made to the building in 1964

- $\quad$ Addition of foyers and terraces to the riverside of the building

- $\quad$ Adding the footprint of the building by $30 \mathrm{ft}$.

- $\quad$ Alterations of façade

- $\quad$ Alteration of the building's entry.

- $\quad$ Addition of concrete walkways around the building (Journal, 2007)

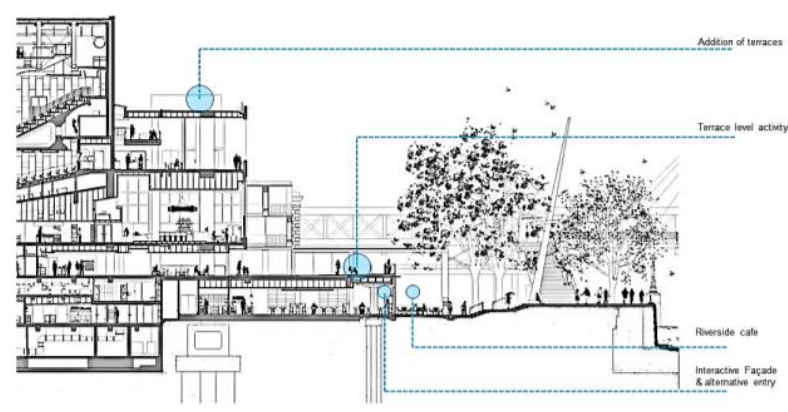

Figure 22 The blow-up section of Riverside (Bianchini, 2019, adapted by Author)

The redevelopment in 2005 in the RFH was mainly internal for the auditorium and other areas. Commercial units and administrative offices were placed. Shops and restaurants were placed in front of the river.

Fig $22 \& 24$ are the sectional view of RFH. The blow-up section mentions the urban and landscape changes which are visible after the regeneration in 2007. 


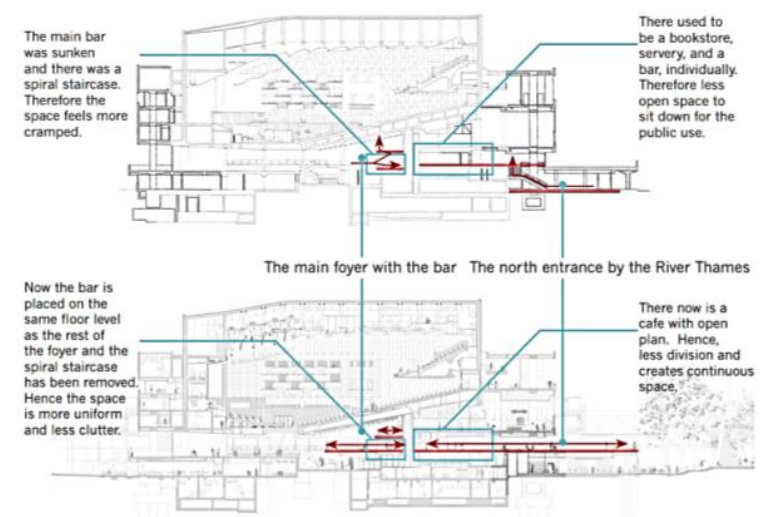

Figure 23 The spatial change after the regeneration (NAGASAKI, n.d.)

Fig 23 shows:

- The interaction between the inside and the outside relationship of the building.

- $\quad$ Dense sectional integration supported by public activities regeneration in the RFH has made the south bank centre more vibrant and inhibited activity. The regeneration is one of the successful ones.

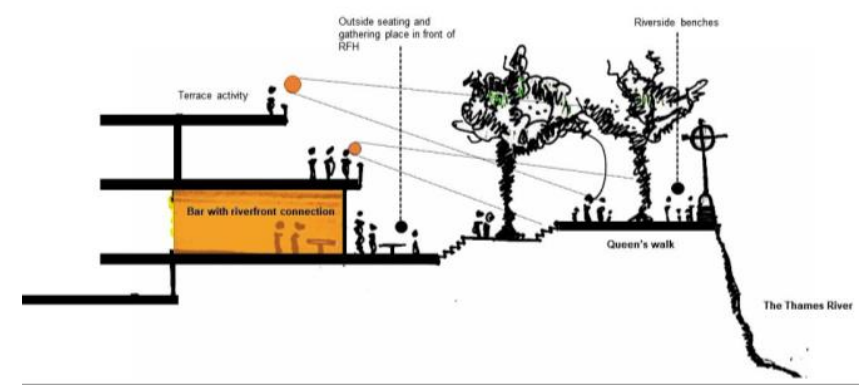

Figure 24 The sectional view of the public realm in front of RFH (Author, 2019)

\section{London Eye}

The London eye is one of the famous landmarks and structures in London. It is a ferries wheel with a height of 135 meters, located on the bank of the river, from which the visitors can see the full view of London. It is situated just beside the Jubilee Gardens (refer to Fig 25) (Designbook, 2011).

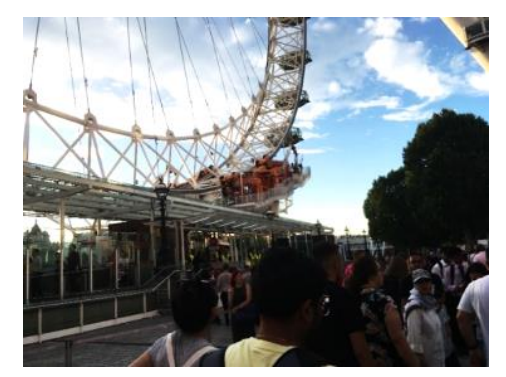

Figure 25 People standing to ride in the London Eye on Friday Evening (Author, 2019)

Critical Analysis of the London Eye:

Although the London Eye has become one of the remarkable landmarks in London, the structure is criticized as well for various reasons, which are the following: 
- Initially, the London Eye was not supposed to be a permanent structure. It had permission for 5 years, but after the period, it was kept as a permanent structure.

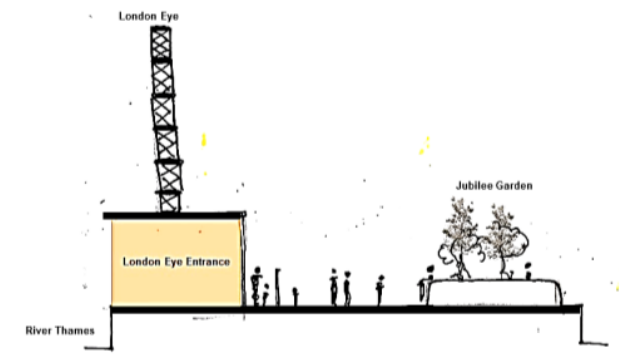

Figure 26 The quality of the public realm in London eye (Author, 2019)

- $\quad$ The London Eye does not represent the history of London and the United Kingdom. It is a ferries wheel for entertainment purpose of the tourists and Londoners.

- While placing the wheel, there was little understanding of urban design and landscape architecture (Turner, 2009).

The public realm completely changes at peak time and off-peak time. The users and the activity are generated only through the London Eye.

\section{Qualitative Public Realm Assessment}

The public realm needs to be assessed in terms of quality. The space syntax of the area shows the quality of the public realm in context with the users.

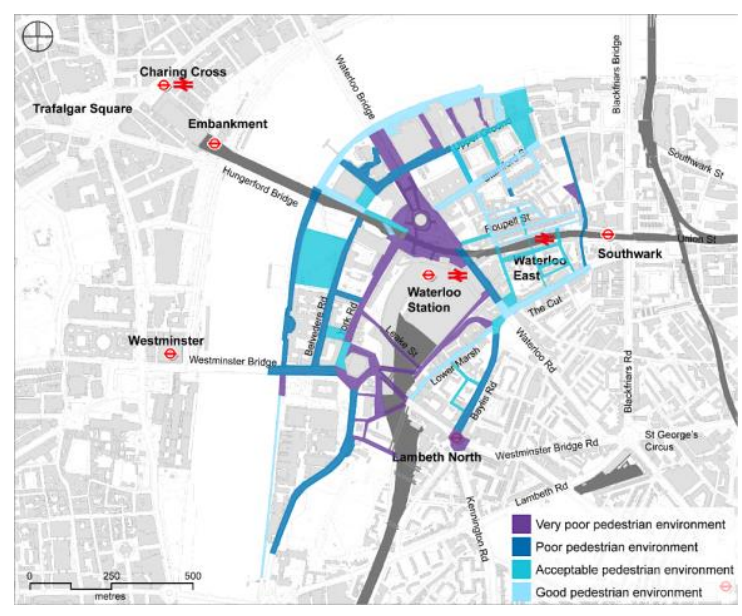

Figure 27 Quality of Public Realm (Syntax, 2011)

Fig 27 shows the area from Westminster Bridge to the area under the Hungerford bridge is considered to be a poor pedestrian environment. The walkway from the Hungerford Bridge to Oxo-Tower Wharf is considered to be a good public realm in terms of user's preference. The South Bank holds a strategic position in central London. The pedestrian linkage diagram shows the connectivity along with the site. 


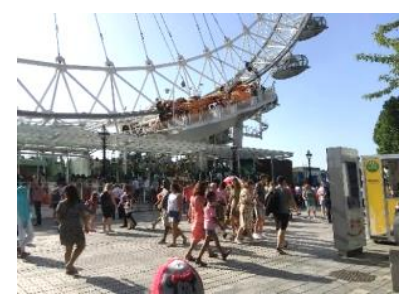

Figure 28 Public realms in front of the London Eye (Author, 2019)

\section{Place Centered Behavioral Mapping}

To understand the spatial analysis and how the public realm works on the bank, three activity monitoring has been done at different days and different times.

Public activity monitoring on Weekend \& Weekdays:

The place centred behavioural mapping is one of the processes to assess the activities in an area. The mapping shows the area is full of activities during a weekend and when the weather is favourable. The images support the upper diagram

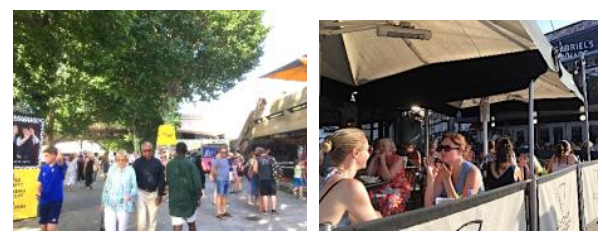

Figure 29 Public activity in front of South Bank Center, and Oxo Tower-Wharf (Author, 2019)

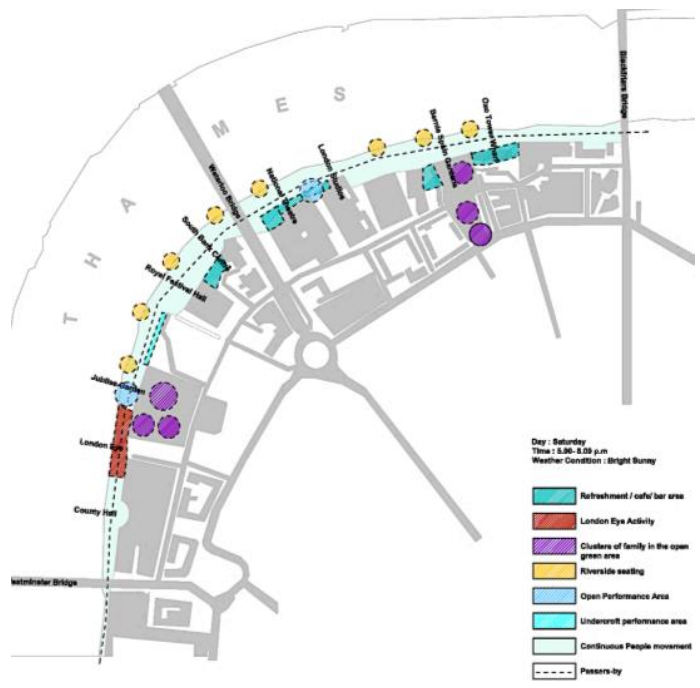

Figure 30 Place centered behavioural mapping on Weekend (Author, 2019)

The place is not too much crowded on the weekdays. However, there are always activities going on in front of the South bank centre, and National Theatre. The public realm in front of the London Eye is still full of visitors, who wants to ride the London Eye. 


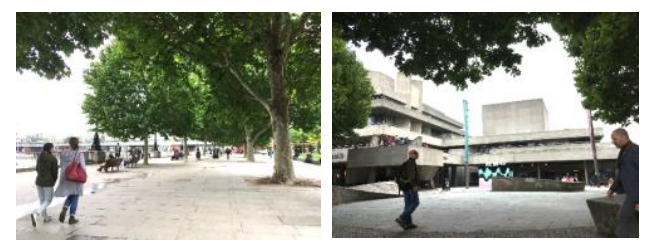

Figure 31 Public activity in Queen's walk, National Theatre (Author, 2019)

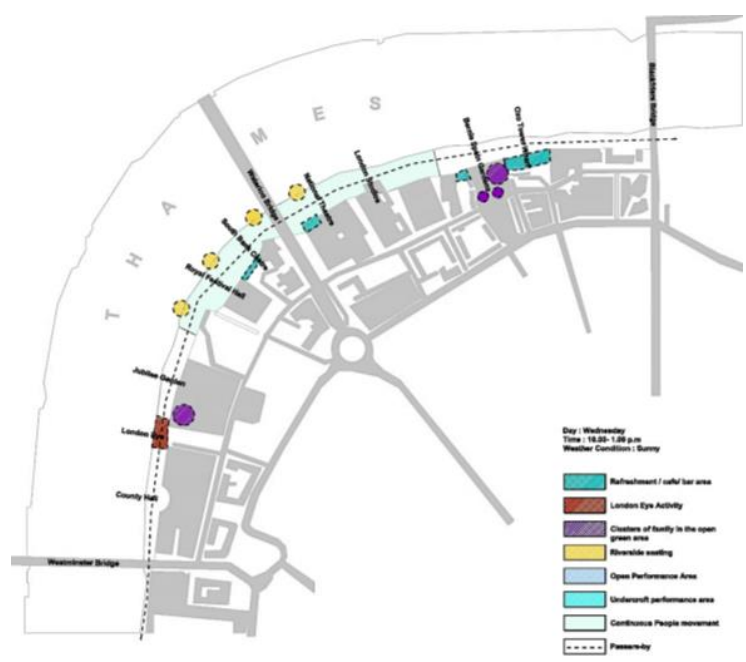

Figure 32 Place centred behavioural mapping on weekdays (Author, 2019)

The Friday night shows a completely different picture at the bank. The public realm in front of the London Eye and Jubilee Garden is empty, whereas, the realm in front of the South Bank Center and NT, are still with different types of activities.

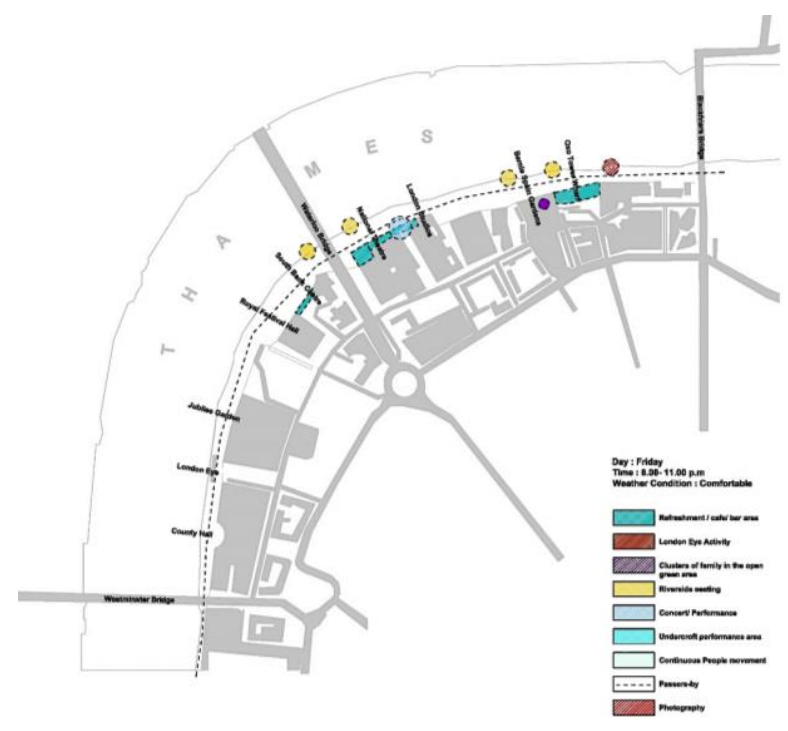

Figure 34 PLace centred behavioural mapping on Friday night (Author, 2019) 

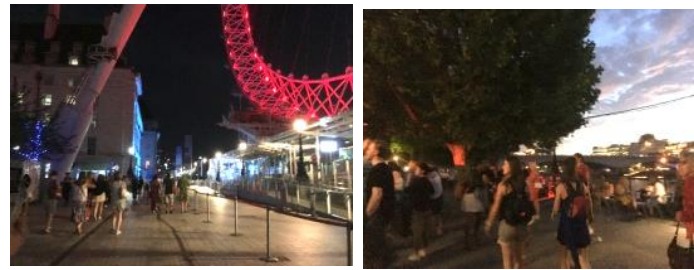

Figure 33 Public activity in front of the London Eye and South Bank Center (Author, 2019)

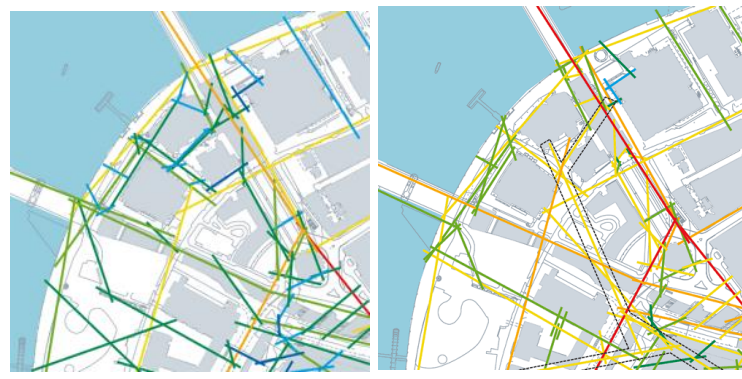

Figure 35 The before-after pedestrian circulation on South Bank (Syntax, 2011)

Fig 35 shows the pedestrian activity before the regeneration and after the development. Before the movement pattern was broken. But after the redevelopment, the realm has given a different experience to the pedestrians which can be analyzed from the latter diagram.

\section{Critical Analysis}

Although on the bank side, it is fully pedestrian circulation, there are different public realms in terms of quality. The width of the realm from Westminster Bridge to Hungerford bridge is thinner than the side of Waterloo Bridge to Black friars bridge. As a result, it creates a funneling effect on a pedestrian walkway (Syntax, 2011).

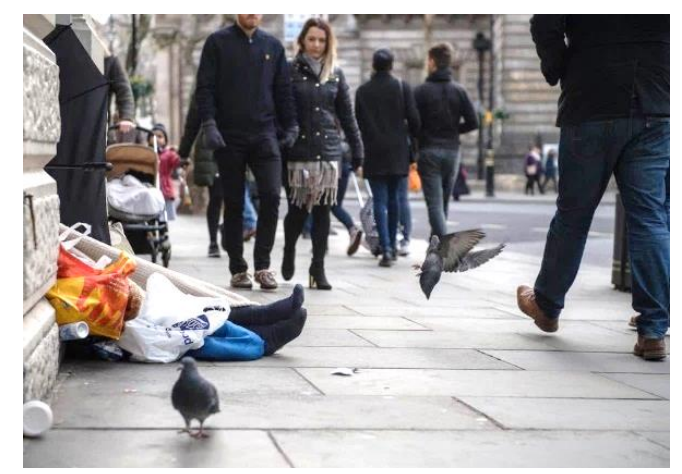

Figure 36 The suffering of the poor hiding under the festivity (Radcliffe. Chris. J., 2018)

The festivity and tourist activity could not hide the sufferings of the people living in the street (refer to Fig 36). The place was once used by slum dwellers and poor people. These people have been executed from the site without managing any home for these homeless people (Independent, 2018).

The key points that the standard UD principles do not include:

- The interaction between the inside and the outside relationship of the building.

- The connection between the destinations

- Dense sectional integration

- The active frontage and connection with the river

- Multi-layered ground condition supported by public activities 
- $\quad$ Promoting the seasonal activities, which makes a place vibrant

- $\quad$ Both PPS and UD principles mention about iconic structures. But the public realm of the London Eye shows it needed proper urban context before placing a ferries wheel as the iconic structure in a culturally and historically important site.

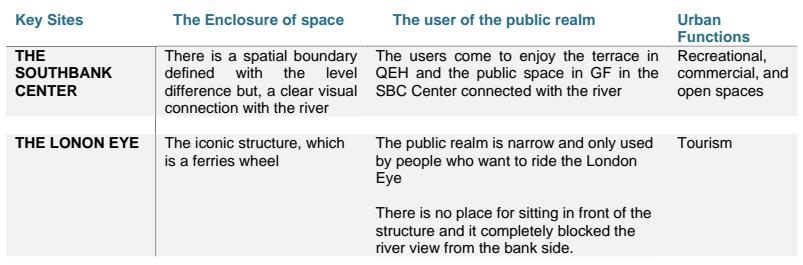

Table 1 Comparative analysis of the key sites in terms of users and functions (Author, 2019)

The public realm in front of SBC is more active and enjoyable with different activities than the public realm of the London Eye. Despite all the negative aspects, South Bank London is one of the successful examples of Waterfront regeneration in the world.

\section{Findings from the theoretical framework and case study analysis}

The brief literature review and case study are discussed to anticipate the importance of waterfronts in urban life and the quality of the public realm in the waterfront. The notion of social inclusion can be achieved with the vitality generated in a place, which follows a certain framework. But regardless of the framework, the place cannot be successful without people. The good quality public realm serves with amenities, connection to the site, safety and other ideas of urban quality. The social impact of urban design is sometimes not identified while implementation of the design which leads to the failure in generating a successful public realm. Jan Gehl has identified the city's greatest attraction is people. According to (Gehl, 2010), the main urban attraction is the activity generated from people. The place needs to be happening for the people to gather. The activities can be a performance, playing music, refreshment or any cultural activities. The relationship between spatial and social are vital to creating a successful city. The social value of urban design increases the preference of users. The regeneration of any place should not just include the framework, but also include the social aspects of urban design. The regeneration of two case studies shows the social impact on the place and the user's preference.

\section{The transformation of South Bank London according to PPS Framework}

Adjusting civic Goals: South Bank London was a war zone before the post-war development. The bank was not considered as the priority for regeneration. After the dockland's regeneration, LCC decided to regenerate the bank. The main objective was to transform the riverfront into a socio-cultural platform. The festival of Britain and the twentieth-century regeneration has made the bank a cultural place which played a very important role in the cultural regeneration in the post-war period.

Vision for a shared community: From Queen's walk, it is evident that, while placing the functions on the bank side, the urban design approach is designated for the users.

Generating multiple functions: From Westminster entry to Black friars' point, there are several functions for different types of people. The tourists mostly the enjoy the ride to London's eye, whereas there are cultural functions linked to Queen's walk through the South Bank Centre and National Theatre mostly provide cultural and relaxation functions to the people. A bund was built to prevent flooding from the river, which was a vision for the community living in the area.

Restricting residential improvement: The land use pattern around the bankside shows that the buildings hold mostly cultural, commercial and recreational functions. The PPS Framework indicates that the good waterfronts 
are not monopolized by residential functions. It limits the diversity of activities in front of the waterfront and prevents 24 hours of activities due to privacy issues (PPS, 2019). The south bank neighbourhood follows the land use framework.

Increasing public access \& Bridging the destinations: The South Bank is located at the centre of central London. It is connected with different modes of transportation. There are three main stations connected to the site, which are Westminster, Waterloo, and Black Friars Underground station. The area is connected by Belvedere Road at the lower level. The public bus and the tube are the main source of public transportation to the site.

Designing buildings to connect public spaces: The SBC has regenerated the ground floor areas of the buildings to activate the place. The connections have been made with the riverside by installing bar and restaurants and public functions.

Seasonal activities: There are many festivals and seasonal activities, that goes on Queen's walk at several times of the river. These festivals are temporary and different activities generate animation in the site (refer to Fig 37).

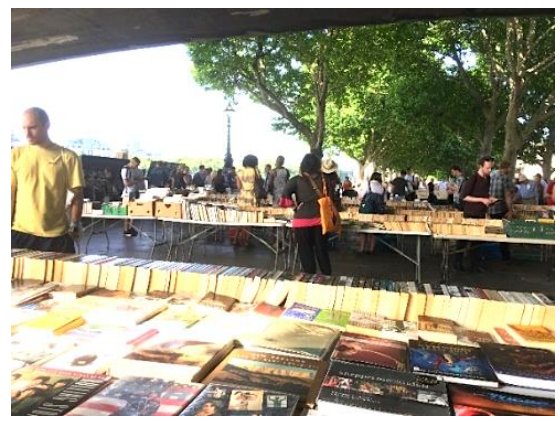

Figure 37 Book Festival going on under the Hungerford Bridge (Author, 2019)

Stand-alone iconic structures: The stand-alone iconic structure in the site is the London Eye, which is a controversial structure. As discussed previously, the London Eye generates tourism, but the placement of the iconic structure did not involve the context of urban design. The public realm in front of the London Eye is considered as a bad quality public realm (Syntax, 2011). Although the PPS framework suggests establishing an iconic structure on the site to generate activity, it needs to meet the urban context of the site before placing a landmark or iconic structure.

\section{Critical evaluation in terms of the good quality public realm}

The high-quality public realm needs to share some qualities. According to (Carmona, 2014), there are some normative principles which can make a public space, a good quality public realm. The waterfront regeneration has started in the 1970s. After the regeneration, it faced a declination due to lack of evolving public realm. After the declination, after the 1990s, the regeneration started again to make the public realm acceptable and robust to its users. The community uses the place and generate animation. The place should be able to offer activities and encouragement to its users. The social interaction on a public realm depends on the major functions provided at the place. The natural environment can be enhanced by the bio diversified landscape and it can enhance the user's preference (Australia, 2014). The activity nodes and entry points from the public transport nodes are very important when it comes to generating an animation. The movement pattern in the site, pedestrian, bicycle movement, and service circulation pattern help to create social, functional and recreation connection. The vehicular and pedestrian movement needs to be in harmony (Carmona, 2014). The streetscape and landscape pattern in the waterfront create harmony between the soft pavement and hard pavement on the site (Australia, 2014). The good quality public realm in waterfront holds some characteristics (Ipswich, 2018). The South Bank London in terms of Qualitative Public Realm South Bank London is a cultural hub for the city. The cultural 
buildings strengthen the cultural activity in the site. Many street performances happen on the Queen's walk which helps to celebrate public life. The pedestrian walkway in front of the river provides the opportunity for the temporary marketplace, food stalls, and other local business activities. There is separate pedestrian and vehicular movement in the site, which makes the public realm safe for all types of users. The public realm in South Bank has several destinations, which increase the legibility of the site. The place is well designed for users. The realm in front of the London Eye doesn't hold good quality public realm, but it generates economic values. The realm in front of the SBC shows a hierarchy in the place arrangement. There is a level difference for different activities in the realm, which connects the riverside greenway with the cultural buildings.

\section{Critical evaluation of the social aspect of waterfront}

(Rauno Sairinen, 2005) has argued that the social impact on the waterfront helps to generate activity, which is often neglected. The framework suggests four major points: Resources and identity, Access and activity, Social status and social experience.

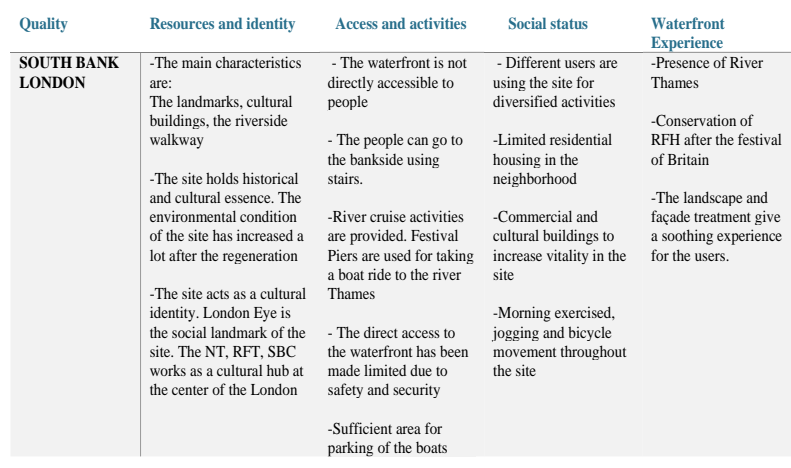

Table 2 Analysis of the case studies in terms of social extent in the waterfront (Author, 2019)

According to (Gehl, 2010) to achieve vitality in any place, there should be vitality, safety, and sustainability. The city needs to be lively. The public spaces have to be active and users need to interact with the spaces. The social and recreational activities should be supported by good pedestrian and vehicular connection and convenience to engage in urban movements (Gehl, 2010). The discussion brief analysis in Chapter 3 and the discussion in Chapter 4 shows, the greater extent of social aspects in a public realm. To activate a place, the urban design, infrastructure, landscape design, implementation of policies, ability to evolve and many other things are needed.

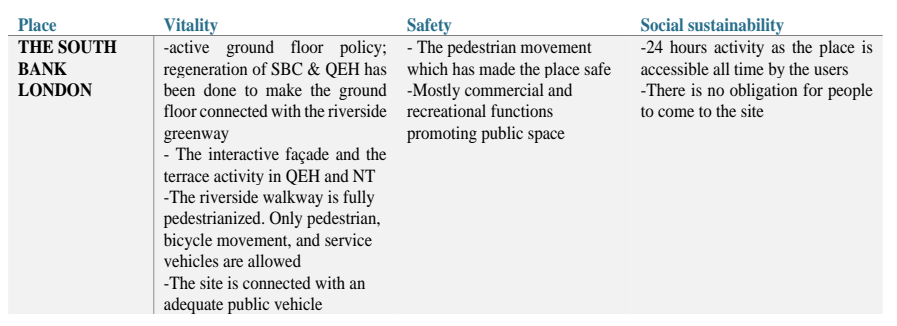

Table 3 Vitality Safety and sustainability of the two waterfronts (Author, 2019) 


\title{
Policy Implementation
}

\author{
Creating A Bund to Prevent Flood \\ Entry Points to Site \\ Public Transportation \\ Pedestrian and Bicycle Circulation \\ Ground Floor Connection \\ Interactive Facade \\ Provision for Local Business \\ Landmark \\ Landscaping \\ Safety \\ Maintenance
}

From the upper discussion, it is evident that there are some strategical design decisions which need to be taken to activate a place socially and economically, which are given below:

- The control between pedestrian and vehicular circulation.

- $\quad$ Provision of Historical Landmarks to create a place identity.

- $\quad$ Active Ground Floor policy with the riverside

- $\quad$ Proper shading with trees or building podiums for shelter and enjoying the riverside.

- $\quad$ Safe and well-lit public area, so the users can use the place for 24- hours.

- $\quad$ Provision for temporary markets, food stalls, and other small local business to generate employment as well as tourism.

- $\quad$ Multi-layered Ground condition

- The inside and outside relation of the buildings through dense sectional integration to generate the urban connection.

From the understanding of the theory and case studies, these are the probable suggestions to activate a place socially and generate animation in the waterfront. In the general UD Criteria and PPS Framework, the upper points are missing, which is seen in the case study analysis. The standard UD criteria do not follow the principles of the successful public realm, which often leads to the declination of the waterfront area. It discusses the social extent, safety, and vitality in the site, which is not followed in the PPS Framework and UD Criteria. The principles of the good quality public realm and the social aspects should be taken into consideration to create a successful public realm in the waterfront.

\section{Opportunity for Future Research}

The study area is situated in the capital of Bangladesh. Bangladesh is a small country situated in south-east Asia. Bangladesh is a riverine country and the capital is encircled by four rivers, the Buriganga, the Shitalakhya, the Balu and the Turag. The site is located on the bank of Buriganga near the water-port terminal.

The mixed-use buildings are typically wholesale markets on the ground floor and residence on the upper floor. The ground floor market and distribution storage have a better connection with the river, which eases the circulation of the goods (Khan, 2012). The Buckland embankment road is used for loading and unloading of the commercial goods. The sectional diagram shows the flow of commercial goods transferring from Mixed-use storage toward the river (Rahman, 2013). 


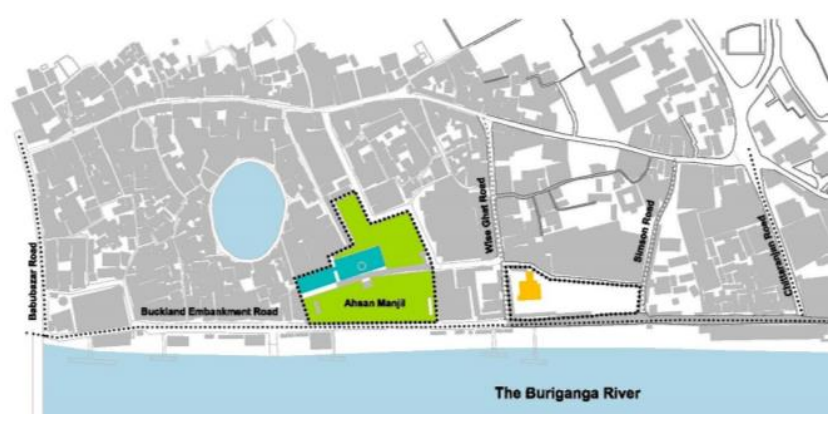

Figure 40 The landmarks at the riverfront (Author, 2019)

The major circulation is across the Buckland Embankment Road, Babubazar road, Chittaranjan Road and North Brook Hall Road. These roads are used for both pedestrian and vehicular movement. These roads are directly connected with the city. The Simson road, the Wise Ghat road, and the Ahsanullah road are connected with the local neighbourhood. There are internal roads, which are passively connected with the local neighbourhood and mostly pedestrian. Chapter five discussed a brief idea about the social, economic and infrastructure problem of the waterfront located on the bank of River Buriganga in Dhaka, Bangladesh. The key points from the understanding of the research will give the research problem a base to start with. There are social, economic and physical issues, which needs to be addressed and gives scope for thorough research to solve the problems in the area.

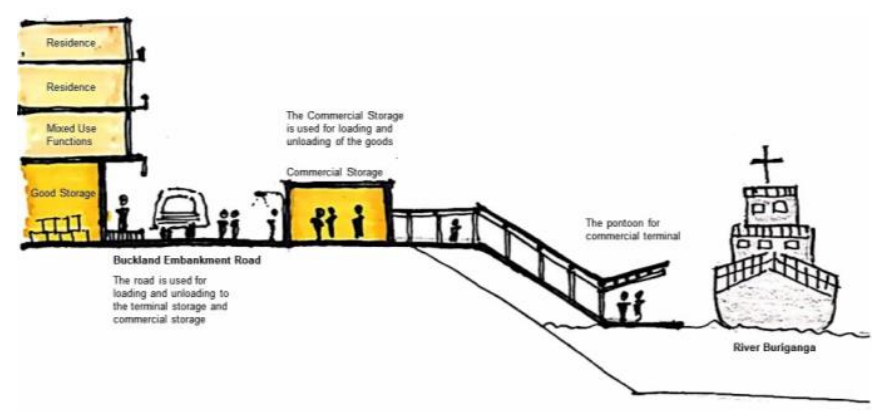

Figure 41 The sectional view between the mixed-use structure and the river (Author, 2019) 


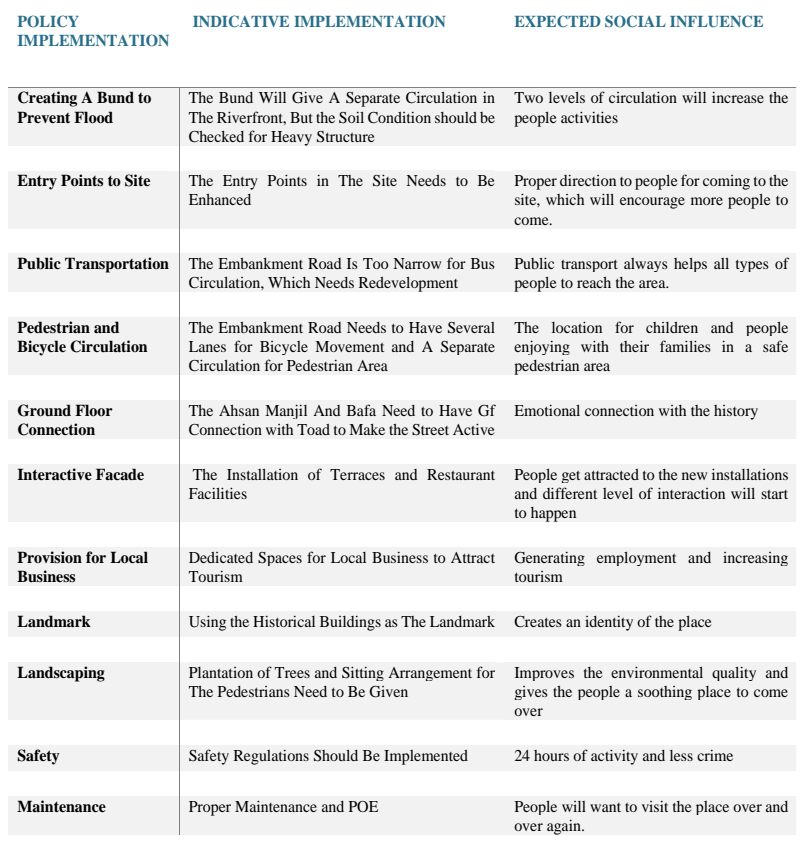

Table 4 Expected social influence of the policy implementation structure on the study area (Author, 2019)

Groundwork before regeneration:

For the implementation, the, following actions needs to be taken first:

- Removal of waste from the river

- $\quad$ Refurbishment of Buckland Embankment Road

- $\quad$ Conservation of the landmarks of the institutional buildings

- Defining pedestrians and vehicular circulation

- Removal of illegal commercial structures

- Designating a proper warehouse space for commercial storage

- Limiting the loading /Unloading in the Embankment road.

The findings from case studies will help to accumulate the social aspects of the proposed regeneration proposal.

\section{Conclusion}

The research concludes with a deep understanding of the importance of social values in the public realm of waterfront. The study looks into the theoretical framework of urban waterfront regeneration and the thorough analysis of the case studies focuses on the importance of social values that controls the success of a public realm. The critical evaluation of the importance of social value in context with the theoretical framework successfully identifies the positive and negative aspects of urban design of a waterfront.

The case study has witnessed declination and then rise after regeneration for people according to the user's preference. The historical background and the regeneration policies shed light on the design decisions in an urban context. The spatial analysis shows, how one public space can be used in different ways by different 
people in a different time. It also shows the importance of land use to activate public space in context with social issues. The physical transformation can change the nature of the public if the user's point of views is also considered in the design decisions. While designing a public realm in waterfront, the social context needs to be considered. The case study used place centred behavioural mapping, imaging of the place and self-experience to analyze the area. From the critical evaluation in terms of the public realm and social aspect of waterfront, it is understood, that the degree of interaction between the inside and outside of the building plays a vital role in activating the waterfront. The multi-layered ground connection should be supported by public activities results in the degree of interaction. The observations from the case study show that the standard urban design criteria do not fulfil the requirements for regeneration to make it successful. The social aspects of a realm and the normative principles along with the urban design criteria will help to generate a successful public waterfront.

The research identifies the principles of waterfront regeneration considering the local context and social aspects of a place. The sense of a place in intangible to measure, but it is necessary to understand the place and evaluate the place accordingly. The research generated some key points to activate the public realm in a waterfront area. The social aspects of a place help to shape the economic value of a place. It gives a brief idea to look into the frameworks and evaluation method to assess the public realm in a waterfront. Also, it critiques the PPS framework and urban design criteria with the understanding from the case study. From the critical evaluation, it is evident that the urban design changes with time and the place needs the ability to evolve with the change of users and time. The general Urban Design criteria should be supported by the principles of the good quality public realm and social aspects should be considered. The research can be taken further to analyze the study area and critically evaluate the design decision for the ongoing Government project of the public realm project on the bank of the river in Dhaka, Bangladesh. The social values are the key aspects to bond people. The contribution of this research will help in generating a public realm in a populated area with consideration of the social aspects of urban regeneration.

\section{References}

Atkins, 2018. Public realm design. [Online]

Aelbrecht, P. S., 2017. The complex regeneration of post-war modernism: London's Southbank Centre's Masterplan. Macmillan Publishers Ltd., 22(4).

Australia., South, Local Govt. Association., 2014. Public Realm: Urban Design Guidelines. [Online]

Bianchini, R., 2019. Hayward Gallery - Southbank Centre, London. [Online]

Bruttomesso, R., 2001. Complexity on the urban waterfront in R. Marshal(ed) Waterfronts in post-industrial cities. London and New York, NY: Spon Press.

Carmona, M., 2014. Re-theorizing contemporary public space: a new narrative and a new normative. Journal of Urbanism: International Research on Placemaking and Urban Sustainability, 8(4).

Cousins, S., 2017. Bringing light to the Southbank Centre. [Online]

Department of Planning and Design of Edge Environments, S., 2012. Waterfronts Open Spaces and Interfaces, s.l.: s.n.

Designing Building wiki, 2019. Public Realm. [Online]

Farrell, T., 2010. Shaping London. West Sussex: John Wiley and Sons, Ltd,

Gehl, J., 2010. Cities for People. Washington DC: Island Press.

Hussein, M. M. F., 2015. Urban Regeneration and the Transformation of the Urban Waterfront: A Case Study of Liverpool Waterfront Regeneration, Nottingham: University of Nottingham.

Ipswich, L. P., 2018. Town Centre and Waterfront -Public Realm Strategy: Supplementary Planning Document, Ipswich: s.n.

Jacobs, J., 1961. The Death and Life of Great American Cities. London: Vintage Books. 
Journal, T. a., 2007. The Royal Festival Hall refurbishment, s.l.: s.n.

Khan, S. P., 2012. Riverfront Redevelopment in Dhaka: Reviewing the Prospects of River Buriganga. Department of Urban and Regional Planning: Bangladesh University of Engineering and Technology, Bangladesh.

Lynch, K., 1960. The Image of the City. Cambridge: MA, MIT Press

Ilieva, E., 2012. Blogger. [Online]

Leventhal, F. M., 1995. A Tonic to the Nation": The Festival of Britain, 1951. Albion: A Quarterly Journal Concerned with British Studies, 27(3).

PPS, 2019. Project for public spaces. [Online].

Montgomery, J., 1998. Making a city: Urbanity, vitality, and urban design. Journal of Urban Design, 3(1).

Project for Public Spaces, 2009. How to transform a waterfront. [Online]

Rahman, F., 2013. Interface Between The River and The City in a Historic Mixed-Use Urban Context: Comprehensive Urban Waterfront Development Design Strategies in The Context of Dhaka, Bangladesh., Calgary, Alberta: Faculty of Environmental Design.

Rauno Sairinen, S. K., 2005. Assessing social impacts in urban waterfront regeneration. ScienceDirect, 26(1).

Shamsuddin. S, Abdul Latip N. S, \&. Sulaiman A. B., 2008. Waterfront regeneration as a sustainable approach to city development in Malaysia. WIT Transactions on Ecology and the Environment: Universiti Teknologi, Malaysia City Campus, Kuala Lumpur, Malaysia, International Islamic University of Malaysia, Malaysia, ISSN 1743-354(DOI: 10.2495/SC080051).

Smith, P. N. a. I., 2000. Cultural Production, Place and Politics on the South Bank of the Thames. International Journal of Urban and Regional Research, 24(1).

Syntax, S., 2011. Space Syntax: Urban Masterplan. [Online]

Timur, U. P., 2013. Urban Waterfront Regenerations., Intechopen.com DOI: 10.5772/55759 [Online]

Tompkins, H., 2008. Conservation Management Plan for the National Theatre: Final Draft, London: Haworth Tompkins Ltd.

Yassin, A. B., Chris.E. \& Mcdonagh. J., 2010. An Evolution of Waterfront Development in Malaysia. 16th Pacific Rim Real Estate Society Conference Wellington. 